\title{
SPECTROFLUORIMETRIC DETERMINATION OF EOSIN CHEMILUMINESCENCE SYSTEM FOR THE ANALYSIS OF DABIGATRAN IN PHARMACEUTICAL FORMULATIONS
}

\author{
DHANAPAL Y*, SRUDHIVINOD V, MOHAMAD WASEEM A
}

Department of Pharmaceutical Analysis, PSG College of Pharmacy, Coimbatore, Tamil Nadu, India. Email: dhanapalpharma1994@gmail.com

Received: 01 October 2019, Revised and Accepted: 16 November 2019

\begin{abstract}
Objectives: The objectives of this study were to develop a rapid, simple, and economical spectrofluorometric method for quantification of dabigatran from marketed formulation and its principle involved based on the protonated process of a binary mixture complex formation with eosin Y.

Methods: A simple and precise spectrofluorometric technique was applied for the method development. It depends on measuring the quenching effect of the drug on the native fluorescence of eosin at excitation under the optimum reaction conditions.

Results: The reaction linear calibration graph constructed between the fluorescence quenching valves flouresence intensity $(\Delta \mathrm{F})$ and the concentration ranges of $5-50 \mu \mathrm{g} / \mathrm{ml}$. Spectrofluorometric analytical performance was validated by accuracy, precision, and specificity, and the results were satisfactory.
\end{abstract}

Conclusion: This method was to develop a fast, simple, and economically applied successfully for the assay, and qualification of dabigatran tablet contains drug, also with different coformulated pharmaceutical formulations.

Keywords: Spectrofluorometric method, Dabigatran mesylate, Eosin Y.

(C) 2020 The Authors. Published by Innovare Academic Sciences Pvt Ltd. This is an open access article under the CC BY license (http://creativecommons. org/licenses/by/4. 0/) DOI: http://dx.doi.org/10.22159/ajpcr.2020.v13i1.35933

\section{INTRODUCTION}

Dabigatran is an aromatic amide obtained in thermal condensation of a carboxy group, chemically dabigatran (2-[\{(4-carboxylic phenyl) amino) methyl 1)-1-methyl-1H benzimidazole-5-carboxylic acid with the secondary amino group of $-\mathrm{N}$-pyridine-2yl-beta-alanine. The active moiety of prodrug dabigatran mesylate, it uses with coadministration of P-glycoprotein inhibitor risk of developing adverse drug reactions such as kidney dysfunction and high body mass index $[1,2]$.

\section{Need of the study}

A literature search revealed only few quantitative analytical methods for the estimation of dabigatran. Further, few methods only described the quantification of dabigatran in biological fluids, as these methods include liquid chromatography-mass spectrometry (LC-MS) with require expensive instruments not available in the conventional bioanalytical laboratory. Dabigatran high-performance LC-MS/MS methods affected the sensitive for analysis of dabigatran in biological fluids [3,4]. However, their sophisticated instrumentation and high cost of analysis limit their use for analysis of drugs. At through, the spectrofluorometric is a highly specified sensitive and simple technique $[5,6]$. However, up to now, no method has been reported in the spectrofluorometric determination of dabigatran. Eosin $\mathrm{Y}$ is known to react in the primary functional groups of alcohols and amines, imidazole's, and thiols. Hence, eosin Y has been used as a fluorogenic reagent to the determination of many pharmaceutical compounds $[7,8]$. In this present study, we devloped chemiluminesence system quantification technique following by dabigatran binary complex formation has been based on its reaction; photon-induced reduction of eosin $\mathrm{Y}$ in acetate buffer ( $\mathrm{pH} 4.0)$ solution. The free fluorescent producer which is measured by fluorimetrically at (329 nm to $519 \mathrm{~nm})$. Hence, we develop a fast, simple, and economical method for quantification of dabigatran from the marketed formulation. The developed method was validated as per under the US FDA guidelines.

\section{METHODS}

Dabigatran mesylate was kindly supplied by Madras Pharma (Chennai); eosin Y and carboxyl methylcellulose (CMC) (Fine Chem Industries,
Mumbai - 600 005), sodium acetate (Lab Chem Pvt., Mumbai), orthophosphoric acid (OPA) (Thermo Fisher Scientific Pvt., India), and eosin $\mathrm{Y}\left(0.5 \times 10^{-4}\right) \mathrm{M}$ aqueous solution were freshly prepared in distilled water. Acetate buffer solution was prepared by mixing an approximate volume of $2 \times 10^{-3} \mathrm{M}$ sodium acetate, and $0.1 \mathrm{M}$ OPA - adjusting to $\mathrm{pH}$ to 4.0 using $\mathrm{pH}$ meter. Carboxymethyl cellulose was prepared as $0.50 \% \mathrm{w} / \mathrm{v}$ by dissolving the small amount in hot water $\left(80^{\circ} \mathrm{C}\right)$ with continuous string (magnetic stirrer) $15 \mathrm{~min}$ and then chilling to $5^{\circ} \mathrm{C}$ for $80 \mathrm{~min}$. All the materials and reagents were of analytical grade and all solutions were prepared with distilled water.

Pharmaceutical formulation

Pradaxa-110 mg and $150 \mathrm{mg}$ capsules Anteka Healthcare Private Limited (New Delhi).

Preparation of dabigatran mesylate standard solution

A stock solution of dabigatran mesylate was prepared by weighing accurately $10 \mathrm{mg}$ of drug transferred in clean dried $10 \mathrm{ml}$ volumetric flask and adds an approximate volume of water and sonicates $15 \mathrm{~min}$ and completed to $10 \mathrm{ml}$ with distilled water. The marking standard solution was prepared by further dilution of the stock solution with the same solvent to obtain concentration required range. The solution was stable at least 1 week when kept in the refrigerator

\section{Preparation of sample}

Dabigatran mesylate marketed sample was prepared by weighing accurately $80 \mathrm{mg}$ of drug transferred in clean dried $10 \mathrm{ml}$ volumetric flask and adds an approximate volume of water and sonicates $30 \mathrm{~min}$ make up to the volume. The solution passed through a $0.45 \mu \mathrm{m}$ syringe filter then the sample solution using further dilution with the same solvent to obtain concentration required range.

\section{General recommended procedure}

One milliliter of sample or standard dabigatran solution concentration $(5-50 \mu \mathrm{g} / \mathrm{ml})$ was transferred into a $10 \mathrm{ml}$ calibrated volumetric flask, followed by $1.0 \mathrm{ml}$ of eosin solution $\left(5.0 \times 10^{-4} \mathrm{M}\right), 0.50 \% \mathrm{w} / \mathrm{v}$ of CMC solution, and $1.0 \mathrm{ml}$ of $2.0 \times 10^{-3}$ acetate buffer $(\mathrm{pH}-4.0)$. The volumes 
were completed up to the mark with distilled water. The emission of the solution was measured at $519 \mathrm{~nm}$ after excitation at $339 \mathrm{~nm}$. The difference in the $\Delta \mathrm{F}$ was plotted versus the drug concentrations.

\section{Procedure for validation of the proposed}

\section{Construction of calibration}

The dabigatran mesylate standard solution having a different concentration $(5-50 \mu \mathrm{l} / \mathrm{ml})$, the fluorescence intensity $(\Delta \mathrm{F})$ was measured for each concentration and the calibration graph was constructed between concentration and $\Delta \mathrm{F}$. Analytical parameter such as correlation coefficient, slope, and intercept was calculated and applying to the linear regression equation. A limit of detection (LOD) was calculated using LOD $=3 \sigma / \mathrm{s}$, which limit of quantitation (LOQ) $=10 \sigma / \mathrm{S}$, where $\sigma$ is the standard deviation of intercept and $\mathrm{S}$ is the slop or calibration curve.

\section{Accuracy and precision}

In this method, repeatability was investigated by applying the general recommendation procedure using and replicated $(5 \mu \mathrm{l} / \mathrm{ml})$. Respectively, intraday precision was performed by carrying the analysis at the 3 successive times within the same day. Moreover, intermediate (interday) precision was calculated using three replicated at the 3 different environmental successive days.

\section{Determination of molar ratio of the reaction between dabigatran} end eosin Y

Breifly, stoichiometry of the reaction Estimated by job's method following by continues variation under the working condition. Master solution of equimolar solution eosin $\mathrm{Y}\left(1.5 \times 10^{-4}\right)$ and dabigatran was prepared. Series of 1:0 ml portions of the master solution of eosin $\mathrm{Y}$ and dabigatran were up comprising different complementary proportions $(0.1: 0.9,0.2: 0.8 \ldots .0 .9: 0.1,10: 0)$ in $10 \mathrm{ml}$ volumetric flasks. Add 1.0 $\mathrm{ml}$ of carboxylmethyl cellulose surfactant $(0.50 \% \mathrm{w} / \mathrm{v})$ and $0.5 \mathrm{ml}$ of acetate buffer ( $\mathrm{pH} 4.0$ ) was added. The volume was completed to $10 \mathrm{ml}$ with distilled water. In the spectrofluorometric method, fluorescence intensity measured at $519 \mathrm{~nm}$ against reagent blank treated similarly. The emission of the solution was measured $519 \mathrm{~nm}$ after excitation of at $339 \mathrm{~nm}$.

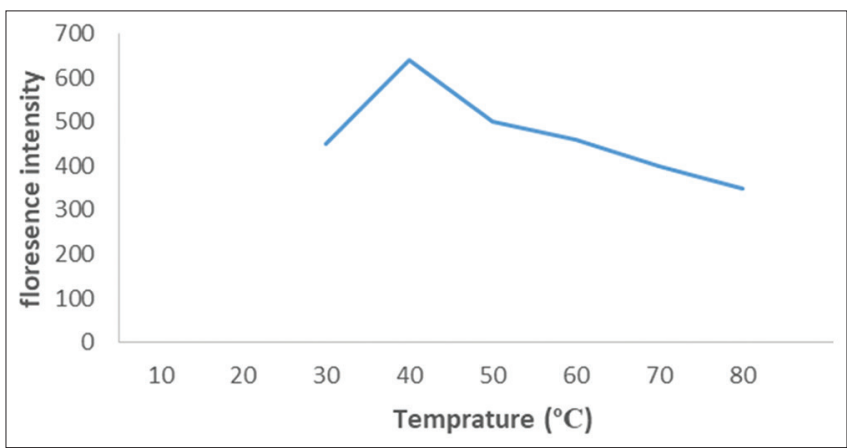

Fig. 1: Effect of temperature in the development reaction of dabigatran and eosin $\mathrm{Y}$

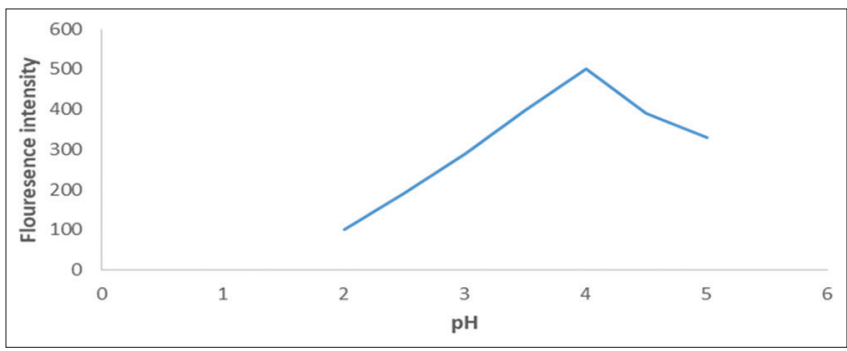

Fig. 2: Effect of $\mathrm{pH}$ on the development reaction product of dabigatran and eosin Y

\section{RESULTS AND DISCUSSION}

Binary mixture complex formed between basic (dabigatran) and eosin Y. The formed complex is low water solubility ion-pair association complex. It was usually extracted with different organic solvents such as methyl tert-butyl ether and dichloromethane. These extraction steps are no formation of the ionic complex. Since alternatively choose surfactant. The surfactant greatly enhanced the water solubility of the complex formation. Hence, this method is aqueous solution no need for any extraction step and direct measurements in this present work, CMC was used a surfactant to improve the wetting solubility of the formation of ion-pair complex. The present study is based on the nitration of dabigatran and eosin $\mathrm{Y}$ at $\mathrm{pH}$ (4.0); the formed complex is mainly due to the electrophilic interaction between the $3^{\circ}$ amino groups in dabigatran and anionic functional group of eosin under acidic $\mathrm{pH}$ (4:0). The formed ion-pair complex is not fluorescent, but the formed complex is accompanied by eosin $\mathrm{Y}$ which is decreased in the native fluorescence intensity at $519 \mathrm{~nm}$ at emission $339 \mathrm{~nm}[9,10]$.

\section{Optimization of reaction conditions}

Various factors affect the formation and stability of the binary complex of eosin Y and dabigatran. The proposed method studied and optimized for the development of the assay procedure. The studied factors induced temperature, concentration of eosin $\mathrm{Y}, \mathrm{pH}$, and the dilution solvents.

It was focused that by increasing the reagent concentration. The $\Delta \mathrm{F}$ was gradually increased. The maximum obtained $\Delta \mathrm{F}$ results in eosin $\mathrm{Y}(1.0$ $\left.\times 10^{-4} \mathrm{M}\right)$.

The temperature influence of fluorescence quenching of the binary complete was studied over the temperature range $\left(10-90^{\circ} \mathrm{C}\right)$, as shown in Fig. 1.

The complex formation was greatly attended by temperature maximum $\Delta \mathrm{F}$ values, was obtained that the stable temperature of the reaction mixture was $40^{\circ}$. The influence of $\mathrm{pH}$ on the $\Delta \mathrm{F}$ quenching of the binary ion-pair complex was studied $\mathrm{pH}$ range (2-7) using the acetate buffer, as shown in Fig. 2.

The complex formation was greatly increased $\mathrm{pH}$ of the maximum $(\Delta \mathrm{F})$ which was obtained that the $\mathrm{pH}$ of the reaction is 4.0 at $40^{\circ} \mathrm{C}$. The reaction between the drug and eosin $\mathrm{Y}$ was completed immediately after mixing of the solution measure $(\Delta \mathrm{F})$ at emission $519 \mathrm{~nm}$ and excitation $339 \mathrm{~nm}$ remain constant. The formed complexing was found to stable for at least $48 \mathrm{~h}$ after dilution, as shown in Fig. 3.

The formed chromogen was diluted with different solvents such as water, ethanol, dichloromethane, and methanol. The water was found to be the most appropriate solvent for dilution. Other study solvents giving lower results (Table 1 ).

\section{Stoichiometry and mechanism of the reaction}

The nature of the binary complex between eosin Y and dabigatran mesylate has been determined by applying the job's method of continuous variation. The concentration reached to the maximum value at a mole fraction of about 1.0, which indicated the formation of a 1:1

Table 1: Maximum excitation and emission wavelength of the binary product (dabigatran/eosin $\mathrm{Y}$ ) with extract in different organic solvents at concentration range $(1000 \mathrm{ng} / \mathrm{ml})$

\begin{tabular}{lll}
\hline Extraction solvent & $\boldsymbol{\Lambda e x} / \boldsymbol{\lambda} \mathbf{e m}(\mathbf{n m})$ & $\begin{array}{l}\text { Fluorescence } \\
\text { intensity }(\boldsymbol{\Delta} \mathbf{F})\end{array}$ \\
\hline $\begin{array}{l}\text { Dichloromethane } \\
\text { Carbon tetrachloride }\end{array}$ & $378 / 491$ & 490 \\
Methyl tart-butyl & $360 / 497$ & 497 \\
ether & $385 / 486$ & 486 \\
Methanol & & \\
Water & $354 / 489$ & 490 \\
\hline
\end{tabular}




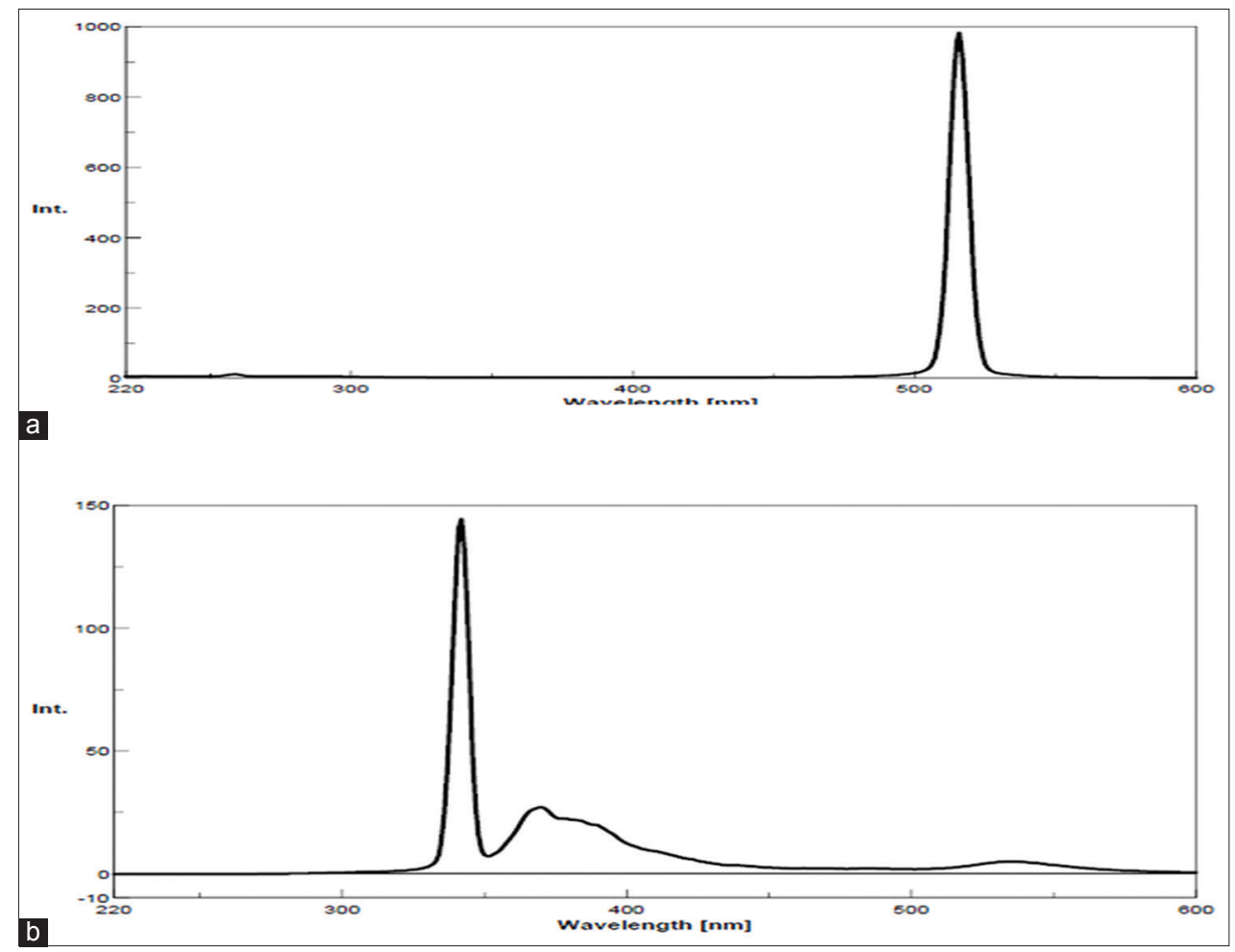

Fig. 3: Binary mixture of dabigatran emission spectrum (a) and excitation spectrum (b)

drug-dye complex depending on the $\mathrm{pH}(4.0)$ of the solution $[11,12]$ Fig. 4.

Eosin $(0)$ denotes the anionic part. The pKa1, pKa2, and pKa3, in the presence of molar concentration, were 2.50, 3.20, and 4.50, respectively. In $\mathrm{pH} 4.0$ weak acidic medium, eosin Y exists mainly in the monovalent anionic form. There are two possibilities for the ionization of eosin, by dissociation of the hydroxyl or carboxylic groups. In eosin analog without bromo substitutions, the carboxylic group is first ionized then followed by a hydroxyl group. The eosin presence of two strong electron-withdrawing bromo groups close to the hydroxyl group reduces the charge density at the oxygen atom of the hydroxyl. Hence, the hydroxyl group tends to dissociate more easily than the carboxylic group. Therefore, eosin monovalent anion is formed by the ionization of the hydroxyl group. Dabigatran has a tertiary amino group that is easily protonated in acidic medium to form a positively charged cation. The ion association complex is formed by the interaction of the protonated tertiary amino group of dabigatran the ionized hydroxyl group of the eosin monoanionic through electrostatic attraction and the hydrophobic forces. The ionic reaction complex formation was confirmed by IR spectra [13,14] (Fig. 5). IR spectrum did not provide more information since several absorption bands for the stretching of $\mathrm{O}-\mathrm{H}$ and $\mathrm{N}-\mathrm{H}$ bonds were observed in the same regions. However, the extinction of characteristic $0-\mathrm{H}$ signals at $1284 \mathrm{~cm}^{-1}$, in the IR spectrum of the reaction product provided that one eosin $\mathrm{Y}$ moiety was attached to the drug molecule at hydroxyl group (Fig. 5).

\section{METHOD VALIDATION}

Quantification, linearity, accuracy, and precision

The optimum reaction conditions and calibration curves were 54 constructed and the analytical parameters were calculated. The LOQ 55 and LOD were calculated according to the ICH guidelines. The present study optimized chromatographic conditions shown in (Table 2).

\section{Linearity}

One milliliter of sample or standard dabigatran solution concentration $(5-50 \mu \mathrm{g} / \mathrm{ml})$ was transferred into a $10 \mathrm{ml}$ calibrated volumetric flask,

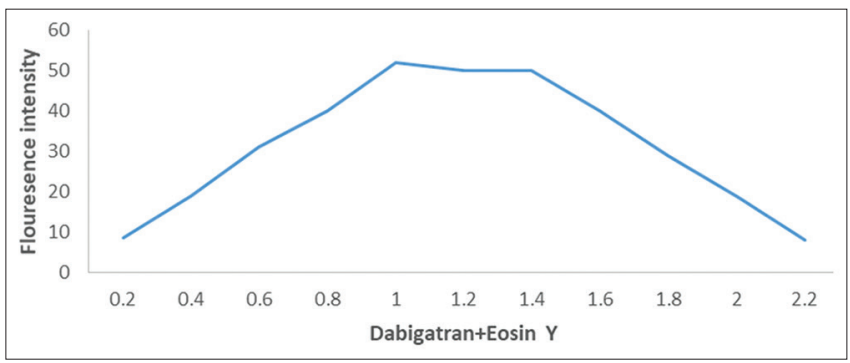

Fig. 4: Molar ratios obtained for the reaction of eosin Y with dabigatran using molar concentration of $1.0 \times 10^{-4} \mathrm{M}$

Table 2: Analytical parameters for the analysis of dabigatran the proposed method

\begin{tabular}{ll}
\hline Parameters & Obtained values \\
\hline Concentration range $(\mu \mathrm{g} / \mathrm{ml})$ & $5-50$ \\
Intercept & 18.43 \\
Slope & 77.60 \\
Correlation coefficient $\left(r^{2}\right)$ & 0.9778 \\
$\lambda$ ex $/ \lambda$ em $(\mathrm{nm})$ & $318 / 519$ \\
SD of slope & 1.07 \\
SD of intercept & 1.54 \\
LOD $(\mu \mathrm{g} / \mathrm{ml})$ & 0.355 \\
LOQ $(\mu \mathrm{g} / \mathrm{ml})$ & 0.813 \\
\hline
\end{tabular}

SD: Standard deviation, LOD: Limit of detection, LOQ: Limit of quantification

followed by $1.0 \mathrm{ml}$ of eosin solution $\left(5.0 \times 10^{-4} \mathrm{M}\right), 0.50 \% \mathrm{w} / \mathrm{v}$ of CMC solution, and $1.0 \mathrm{ml}$ of $2.0 \times 10^{-3}$ acetate buffer $(\mathrm{pH}-4.0)$. The volumes were completed up to the mark with distilled water. The emission of the solution was measured at $519 \mathrm{~nm}$ after excitation at $339 \mathrm{~nm}$. The difference in the $\Delta \mathrm{F}$ was plotted versus the drug concentrations, as shown in Fig. 6.

Precision

Precision studies were estimated at two levels, repeatability and intermediate precision through five replicate analyses of the drug 


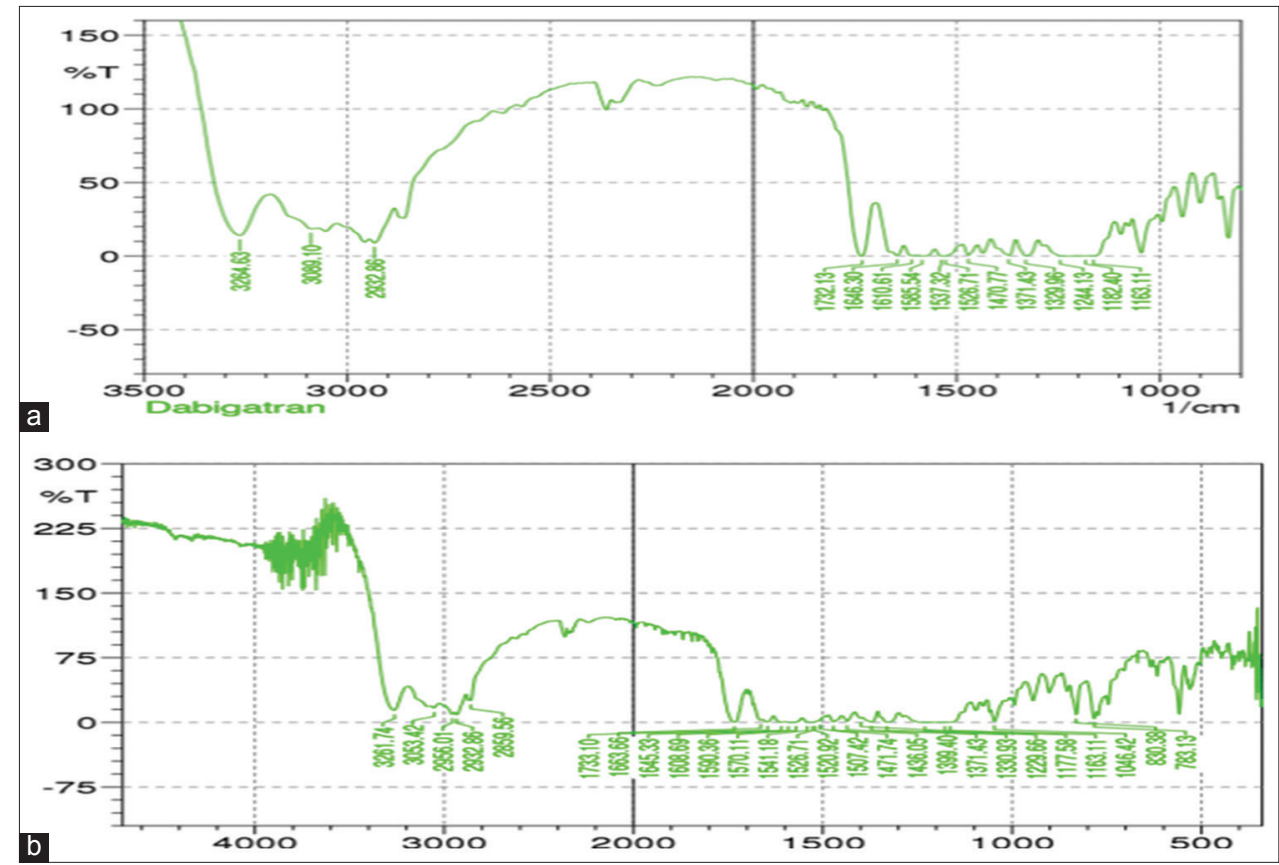

Fig. 5: IR spectrums of the dabigatran and binary complex compound. (a) Standard IR spectrum of dabigatran. (b) Standard IR spectrum of the binary complex

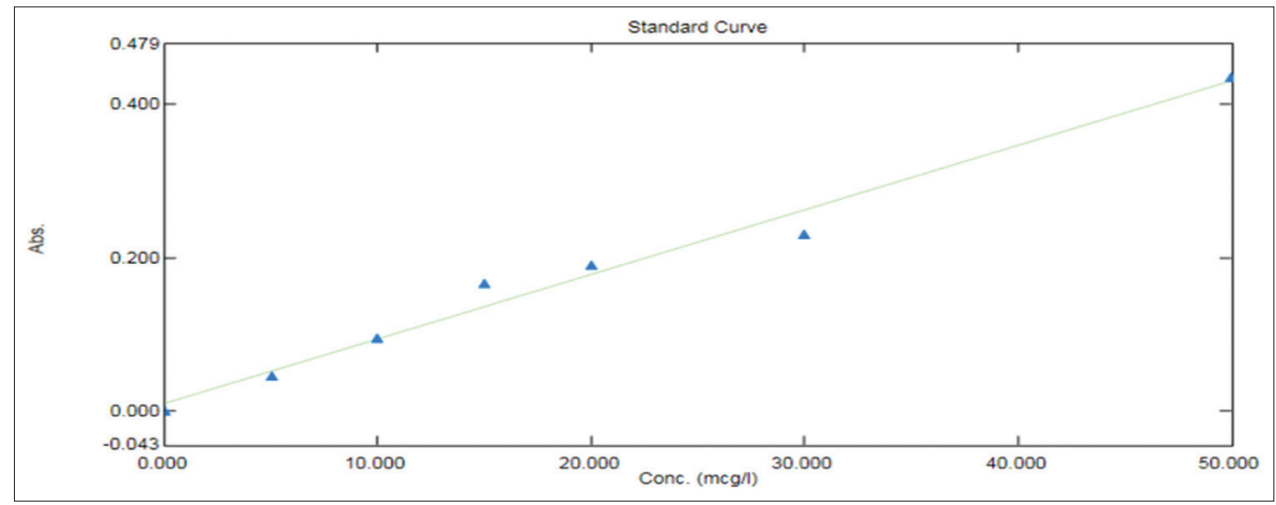

Fig. 6: The linearity spectrum of dabigatran and eosin Y complex

Table 3: Intra- and interday assay of precision of the proposed method for the determination of dabigatran

\begin{tabular}{lll}
\hline Precision & Recovery (\%) \pm SD & RSD (\%) \\
\hline $\begin{array}{l}\text { Intraday precision } \\
\text { Mean } \pm \text { SD }\end{array}$ & $98.58 \pm 0.21$ & 1.12 \\
Interlay precision & & \\
$\quad$ Day 1 & $99.8 \pm 0.81$ & 0.699 \\
Day 2 & $100.83 \pm 0.27$ & 0.831 \\
Day 3 & $100.56 \pm 0.44$ & 1.01 \\
Mean \pm SD & $99.94 \pm 0.25$ & \\
\hline
\end{tabular}

The value of the average of three determinations in proposed method $(n=3)$. SD: Standard deviation, RSD: Relative standard deviation

$(0.5-10 \mu \mathrm{g} / \mathrm{ml})$. The repeatability (intraday precision) was performed by the analysis 3 successive times within the same day; intermediate (interday) precision was performed at 3 successive days. The low values of standard deviations indicated high precision of the proposed methods; the obtained dates are shown in Table 3.

Specificity

The specificity studies of the method were investigated by observing dabigatran marketed condition. The sample was prepared by weighing
Table 4: Specificity analysis of commercial tablets the proposed method

\begin{tabular}{lllll}
\hline Product & Mean \pm SD & Recovery $(\%) \pm S D$ & $\boldsymbol{T}$ & $\boldsymbol{F}$ \\
\hline Pradaxa $110 \mathrm{mg}$ & $110.59 \pm 0.41$ & $100.59 \pm 0.49$ & 0.26 & 0.49 \\
Pradaxa 150 mg & $150.74 \pm 0.26$ & $100.47 \pm 0.19$ & 0.68 & 1.85
\end{tabular}

The value of the average of three determinations in proposed method $(n=3)$.

SD: Standard deviation

accurately $80 \mathrm{mg}$ of drug transferred in clean dried $10 \mathrm{ml}$ volumetric flask and added approximate volume of water and sonicated $30 \mathrm{~min}$ make up to the volume, then after passed through $0.45 \mu \mathrm{m}$ syringe filter. After suitable dilution, the obtained solution was analyzed by proposed methods. Obtained dates are shown in Table 4.

\section{CONCLUSION}

The progression of chemiluminesence spectrofluorometric quantification technique of dabigatran. These methods are simple, sensitive, and environmentally safe since water is the reaction solvent which is the most important green solvent, organic solvents are omitted in the present work and eosin $\mathrm{Y}$ is a less toxic regent. This method is not using expensive solvents and instruments, there is simplicity, the 
sample is extracted with aqueous no need any organic solvents, and the formed eosin Y as an ion-pairing complex was directly measured in the aqueous solution. The devloped method are sensitivity, simplicity and applied for suitable routine analysis of dabigatran marketed formulations.

\section{ACKNOWLEDGMENTS}

The authors are thankful to PSG College of Pharmacy, Department of Pharmaceutical Analysis, for providing all the facilities to carry out this research work.

\section{AUTHORS' CONTRIBUTIONS}

D.Y and M.W conceived the study and design the experiments. D.Y. performed the experiments and analyzed the data; S.V. wrote the manuscript.

\section{REFERENCES}

1. Atrial Fibrillation Investigators. Risk factor for stroke and efficacy of antithrombotic therapy in atrial fibrillation. Analysis of pooled data from clinical trials. Arch Intern Med 2001;154:1449-75.

2. Al-Aieshy F, Malmström RE, Antovic J, Pohanka A, Rönquist-Nii Y, Berndtsson M, et al. Clinical evaluation of laboratory methods to monitor exposure of rivaroxaban at trough and peak in patients with atrial fibrillation. Eur J Clin Pharmacol 2016;72:671-9.

3. Rodina TA, Melnikov ES. HPLC-MS/MS for determining dabigatran in human blood serum. Pharma Chem J 2018;51:57-64.

4. Latha NM, Supriya P. Development validation of RP-HPLC method for the estimation of dabigatran etexilate mesylate (DEM) in bulk form. Int J Pharm Anal Res 2016;5:141-7.

5. Srinivasan V, Sivaramakrishnan H, Karthikeyan B, Balaji T,
Vijayabaskar S. Stress degradation studies on mebeverine hydrochloride and development of a validated stability indicating UPLC method. J Liq Chromatogr Relat Technol 2011;34:1631-44

6. Ravelli D, Dondi D, Fagnoni M, Albini A. Photocatalysis. A multifaceted concept for green chemistry. Chem Soc Rev 2009;38:19992011.

7. Sawyer DT, Sawyer DT, Heineman WR, Beebe JM. Chemistry Experiments for Instrumental Methods. New York: Wiley; 1984.

8. Prier CK, Rankin DA, MacMillan DW. Visible light photoredox catalysis with transition metal complexes: Applications in organic reactions. Chem Rev 2013;113:5322-63.

9. Cheong LW, Heng PW, Wong LF. Relationship between polymer viscosity and drug release from a matrix system. Pharm Res 1992;9:1510-4.

10. Zhang X, Zhang X, Yang B, Win Y. Facile fabrication of aggregationinduced emission based red fluorescent organic nanoparticles for cell imaging. Chin J Polym Sci 2014;32:871

11. Validation of Analytical Procedures: Text and Methodology. 2005

12. Moffat AC, Osselton MD, Widdop B. Clarke's Analysis of Drugs and Poisons in Pharmaceuticals, Body Fluids and Postmortem Material. $3^{\text {rd }}$ ed. London: Pharmaceutical Press; 2004. p. 1189-90.

13. Job P. Formation and stability of inorganic complexes in solution. Anal Chem 1928;9:113-203.

14. Coates J. Encyclopedia of Analytical Chemistry: Interpretation of Infrared Spectra, a Practical Approach. Chichester: John Wiley and Sons Ltd.; 2000.

15. Meyers RA, editor. Validation of Analytical Procedures. Methodology ICH Harmonised Tripartite Guideline Having Reached Step 4 of the ICH Process at the ICH Steering Committee Meeting on 1996. Chichester: John Wiley and Sons Ltd.; 1996. p. 10815-37.

16. Walsh MI, Belal FF, Eid MI, Mohamed SA. Spectrophotometric determination of tizanidine and orphenadrine via ion pair complex formation using eosin Y. Chem Cent J 2011;5:60. 